\title{
The Effects of Reactor Design on the Synthesis of Titanium Carbide-Derived Carbon
}

Michael R. Dutzer, Michael C. Mangarella, Jennifer A. Schott, Sheng Dai, Krista S. Walton*

\section{Abstract}

Titanium carbide-derived carbon with residual metal is synthesized by partial chlorination at 500 ${ }^{\circ} \mathrm{C}$. This partial metal removal in the carbide creates vacancies, about which the carbon reorganizes to form an amorphous, porous carbon structure. To understand the titanium removal process on a bulk scale, three reactor designs were tested: (1) a flow-over horizontal-bed reactor, (2) a vertical flow-through packed-bed reactor, and (3) a fluidized-bed reactor. These reactors were chosen to investigate how various $\mathrm{Cl}_{2}$ flow patterns impact the etching uniformity on individual TiC-CDC particles. Both the horizontal- and packed-bed reactors lost approximately $10-15 \mathrm{wt} \%$ of the original Ti content in $0.5 \mathrm{~h}$ and lost more than $95 \mathrm{wt} \%$ of the Ti content at $3 \mathrm{~h}$ of etching; however, the fluidized-bed reactor lost approximately $85 \mathrm{wt} \%$ of the original $\mathrm{Ti}$ content in $0.5 \mathrm{~h}$ and reached a level of etching corresponding to more than $95 \mathrm{wt} \%$ at $1 \mathrm{~h}$. Additionally, the horizontal- and packed-bed reactors were found to etch the TiC-CDC particles 
non-uniformly, while the fluidized-bed reactor produced samples with uniformly etched particles that followed the core-shell model of Ti extraction.

Keywords: Carbide-derived carbon; Titanium; Partial etching; Reactor design; Core-shell extraction 


\section{Introduction}

Activated carbons are among the oldest and most widely used adsorbents in water purification (Otowa et al., 1997), gas purification (Carter et al., 2011), metal extraction (Johns et al., 1998), and multiple other applications (Matisová and Škrabáková, 1995). Typical synthesis methods include pyrolysis of precursors including wood, fruit pits, and shells to create a hierarchal pore structure. The resulting carbon structures can be chemically tuned through the addition of functional groups or by inserting metal nanoparticles to target specific compounds in post-carbonization treatment processes (Bandosz et al., 1996; Rychlicki and Terzyk, 1998). While these methods are beneficial for adsorption, newer carbon sources have been evaluated to target a narrow pore size distribution in the final porous carbon. A uniform pore size distribution enables more effective molecular sieving, which allows for selective adsorption based upon adsorbate size while other aspects of the carbon material introduce selective adsorption based upon chemical properties.

Carbide-derived carbons are a class of amorphous carbon materials defined by their narrow pore size distribution, which is created through the selective removal of the metal heteroatom from a crystalline carbide structure. This removal or etching process is typically done with chlorine gas at temperatures at or exceeding $400^{\circ} \mathrm{C}$; the chlorine reacts with the metal to form a metal chloride, which immediately enters the gas phase and is removed from the system. The remaining carbon then rearranges around these metal vacancies to form tunable pore sizes based upon the metal atom size, metal configuration within the carbide, and etching temperature (Presser et al., 2011). In addition to a narrow pore size distribution, CDCs offer physical and chemical properties that make CDCs ideal for use in electronic (Chmiola et al., 2006; Portet et al., 2009), adsorption (Presser et al., 2011), and reactive applications (Borchardt et al., 2012). For adsorption applications, the addition of metal nanoparticles is beneficial, as seen with other 
activated carbons, (Rezaee et al., 2014; Tsoncheva et al., 2014) to introduce active sorption sites for the selective adsorption of target molecules. These nanoparticles can be created in a CDC through a partial etching of the carbide precursor, (Mangarella et al., 2014) rather than a postsynthesis impregnation necessary for activated carbons. To control the residual metal loading, composition, and location, and in-depth understanding of the reaction mechanism is of utmost importance.

The reactor design can significantly impact how the metal is removed from the bulk carbide sample by affecting the flow of $\mathrm{Cl}_{2}$ gas at high etching temperatures. Conventionally, CDCs are created in a horizontal flow-over tube reactor (Gogotsi et al., 2003). In this reactor design, chlorine must diffuse through the sample bed to react with the metal. If the reaction kinetics are faster than chlorine diffusion through the bed, layers form (Mangarella et al., 2014). A packed-bed reactor allows chlorine to flow through the sample, which should reduce the effects of chlorine diffusion through the bed. However, uneven etching could still occur through the bed, especially if channels form. A fluidized-bed reactor allows for mixing within the bed based upon differences in density and has not been studied widely in CDC literature (Glenk, 2012). The mixing of CDC particles during etching should negate any chlorine diffusion limitations through the bed and create uniformly etched CDC samples.

Titanium carbide is a well-studied CDC that is known to follow a core-shell model of Ti extraction, where $\mathrm{Ti}$ is removed first from the surface of the particle according to reaction described in equation 1 and then deeper to the particle's core (Becker et al., 2010)

$$
\mathrm{TiC}_{(\mathrm{s})}+2 \mathrm{Cl}_{2(\mathrm{~g})} \rightarrow \mathrm{TiCl}_{4(\mathrm{~g})}+\mathrm{C}_{(\mathrm{s})}
$$

Depending upon the exact reaction conditions, including temperature and chlorine concentration, various products are formed. At higher $\mathrm{Cl}_{2}$ concentrations (greater than $5: 1 \mathrm{Cl}_{2}: \mathrm{TiC}$ ), the 
products are dependent upon reaction temperature. Specifically, at temperatures below $400{ }^{\circ} \mathrm{C}$, $\mathrm{TiCl}_{4}$ and $\mathrm{CCl}_{4}$ are equally thermodynamically favored, while at temperatures exceeding $600{ }^{\circ} \mathrm{C}$, only $\mathrm{TiCl}_{4}$ is thermodynamically preferred. However, these thermodynamic calculations were performed in a closed system, while the reactors tested herein are open systems. This allows for the preferential formation of $\mathrm{TiCl}_{4}$ at lower temperatures(Presser et al., 2011; Yushin et al., 2006). In addition, titanium metal (Hanson et al., 1982) and titanium dioxide (Liu et al., 2005) have shown promise for selectively adsorbing chemicals and is a widely used catalyst. Titanium chloride has not been shown to form metal nanoparticles in literature or act as a graphitization catalyst, which would affect the resulting carbon structure (Leis et al., 2002; Xu et al., 2013). For these reasons, $\mathrm{TiC}$ is a good candidate to understand fundamentally how metal removal on a bulk scale affects individual particle properties. By testing three reactor designs, insight can be gained into controlling the amount and location of residual metal.

\section{Experimental Methods}

\subsection{Materials}

Titanium carbide-derived carbon (TiC-CDC) was synthesized using three different reactors depicted in Figure S1: (1) a horizontal-bed reactor; (2) a packed-bed reactor; and (3) a fluidized-bed reactor. The samples were prepared under similar conditions for all reactors. The reactors were purged with Ar while being heated to $500{ }^{\circ} \mathrm{C}$ at a $5{ }^{\circ} \mathrm{C} \min ^{-1}$ ramp rate. The samples were etched at $500^{\circ} \mathrm{C}$ with a mixture of $1: 4 \mathrm{Cl}_{2}$ :Ar (Airgas, 99.5\% purity; Airgas, Ultra High Purity, respectively) ratio, and the reaction time was varied. The horizontal- and packedbed reactor samples had etching times ranging from $0.50-2.00 \mathrm{~h}$ in $0.50 \mathrm{~h}$ increments with an additional sample etched at $3.00 \mathrm{~h}$, while the fluidized-bed reactor samples had chlorination times ranging from $0.25-1.50 \mathrm{~h}$ in $0.25 \mathrm{~h}$ increments. After the reaction, the reactors were cooled 
under a pure Ar purge. A NaOH scrubber is placed at the outlet of each reactor to neutralize the acidic metal chlorides and unreacted $\mathrm{Cl}_{2}$.

For samples prepared in the horizontal-bed reactor, $2 \mathrm{~g}$ of $\mathrm{TiC}$ (Sigma-Aldrich, 98\% purity, -325 mesh) were placed into a quartz boat and inserted into a quartz tube (OD 1", 20" long) in a horizontal tube furnace. The previously described etching reaction was performed at a total flow rate of $200 \mathrm{~mL} \mathrm{~min}^{-1}$ and an Ar purge flow rate of $160 \mathrm{~mL} \mathrm{~min}^{-1}$. For reaction times less than $3.00 \mathrm{~h}$, two horizontal layers were formed in the sample: a black top layer and a silvery gray bottom layer. These layers were mixed for bulk sample analysis for each reaction time. For layer characterization, an additional sample was chlorinated for $1.50 \mathrm{~h}$, and the layers were manually separated. Samples are identified through their chlorination time, e.g. $1.50 \mathrm{~h}$.

For the packed-bed reactor, TiC-CDC samples were created in a vertical tube furnace. $2 \mathrm{~g}$ of -325 mesh TiC were funneled into a quartz tube (OD 0.75", 28” long) containing a quartz frit (Technical Glass, porosity 1). The samples were prepared using the same reaction parameters as the horizontal-bed reactor. Due to the absence of any noticeable layering and system setup limitations, only bulk sample characterization was performed.

The fluidized-bed reactor is similar to the packed-bed reactor; however, $\mathrm{Ar}$ and $\mathrm{Cl}_{2}$ flow rates and $\mathrm{TiC}$ particle size were increased to ensure bed fluidization. TiC (Inframat Advanced Materials, $99.7 \%$ purity, $+100-60$ mesh) was sieved to have a narrower particle size distribution of $+100-80$ mesh. The same quartz tube used in the packed-bed reactor was filled with two grams of $\mathrm{TiC}$ and then tube placed in the vertical tube furnace. The etching reactions were then performed at a total flow rate of $400 \mathrm{~mL} \mathrm{~min}^{-1}$. The Ar purge was set to $400 \mathrm{~mL} \mathrm{~min}^{-1}$ while the reactor heated and to $320 \mathrm{~mL} \mathrm{~min}^{-1}$ as the reactor cooled. 


\subsection{Methods}

\subsubsection{Power X-Ray Diffraction (PXRD)}

PXRD was used to analyze the crystal structure of the resulting TiC-CDC samples. A PANalytical X-ray diffractometer with a $\mathrm{Cu} \mathrm{K \alpha}$ X-ray source $(\lambda=1.54 \AA)$ was used to obtain PXRD patterns. The samples were evaluated from $15-90^{\circ}$ with a step size of $0.02^{\circ}$. All samples were run at room temperature without activation.

\subsubsection{Nitrogen Adsorption at $77 \mathrm{~K}$}

Nitrogen (Airgas, Ultra High Purity) adsorption experiments were performed at $77 \mathrm{~K}$ on a Quantachrome Quadrasorb EVO to determine the surface areas and pore size distributions. The surface areas and pore size distributions were calculated using the Braunauer, Emmett, and Teller (BET) theory using $0.005<\mathrm{p} / \mathrm{p}_{0}<0.03$ and Quenched Solid Density Functional Theory (QSDFT) assuming slit-shaped pores are present between graphene sheets, respectively (Kleitz et al., 2010; Neimark et al., 2009). QSDFT is a modified DFT model that calculates pore size distribution for disordered carbons and takes into account the heterogeneity of the rough, disordered carbon surface (Gor et al., 2012). Prior to $\mathrm{N}_{2}$ adsorption, approximately $25 \mathrm{mg}$ of sample were outgassed under dynamic vacuum on a Quantachrome FloVac Degasser at $150{ }^{\circ} \mathrm{C}$ for approximately $16 \mathrm{~h}$.

\subsubsection{Carbon Dioxide Adsorption at $273 \mathrm{~K}$}

Carbon dioxide (Airgas, Bone Dry) adsorption isotherms for the fluidized-bed reactor samples were performed at $273 \mathrm{~K}$ on a Micromeritics 3Flex. Non-Linear Density Functional Theory (NLDFT) using 4E-06 $<\mathrm{p} / \mathrm{p}_{0}<0.032$ and assuming slit-shaped pores calculated a pore size distribution. NLDFT is another modified DFT model that calculates pore size distribution based upon partial $\mathrm{CO}_{2}$ adsorption isotherms. Prior to measurement, approximately $30 \mathrm{mg}$ of 
sample were outgassed at $150^{\circ} \mathrm{C}$ for $12 \mathrm{~h}$ under dynamic vacuum using Micromeritics Smart VacPrep System.

\subsubsection{Thermogravimetric Analysis (TGA)}

Residual metal loading was calculated using thermogravimetric analysis (TGA) data, gathered on a TA Instruments TGA Q50. Approximately $30 \mathrm{mg}$ of sample were placed in a platinum sample pan and allowed to equilibrate at $25^{\circ} \mathrm{C}$. Then the sample was heated at $5{ }^{\circ} \mathrm{C}$ $\min ^{-1}$ under air flow (Airgas, Ultra Zero Grade) at $20 \mathrm{~mL} \mathrm{~min}^{-1}$ to a final temperature of $900{ }^{\circ} \mathrm{C}$, which was maintained for $2 \mathrm{~h}$ for the samples created with the horizontal- and packed-bed reactors and for $4 \mathrm{~h}$ for the samples synthesized with the fluidized-bed reactor to ensure the carbon was completely combusted due to the larger particle size. Residual metal calculations were performed assuming that all residual material is $\mathrm{TiO}_{2}$.

\subsubsection{Raman Spectroscopy}

Raman spectra were obtained on a Renishaw system with microscope. Three accumulations, each collected for $40 \mathrm{~s}$, over the spectrum range $100-3200 \mathrm{~cm}^{-1}$ were gathered for each sample using a $514 \mathrm{~nm}$ laser wavelength and 50x objective lens.

\subsubsection{Scanning Electron Microscopy (SEM) and Energy-Dispersive X-ray Spectroscopy $(E D X)$}

SEM images of TiC-CDC samples created in the horizontal- and packed-bed reactors were taken on a LEO 1530 Thermally-Assisted Field Emission Scanning Electron Microscope (TFE-SEM). All samples were prepared by suspending the sample in methanol and drop-casting onto aluminum foil. Images were obtained using an accelerating voltage of $10 \mathrm{keV}$. EDX spectra were obtained using an Oxford-7426 EDX detector attached to the LEO 1530 TFE-SEM. Spectra 
were gathered using an area scan for the horizontal-bed reactor samples and a point scan for the packed-bed reactor samples.

For samples prepared using the fluidized-bed reactor, a cross-section of the sample was prepared and then imaged via SEM. To achieve the cross-section of the fluidized-bed samples for SEM/EDX analysis, the following procedure was followed. Each sample was first mounted in a rectangular microtomy mold using EpoxiCure resin and hardener. This initial mounting step was necessary to maintain the area concentration of particles at an appropriate level. The samples were placed under vacuum at 0.167 bar $(-25 \mathrm{in} \mathrm{hg)} \mathrm{while} \mathrm{they} \mathrm{cured.} \mathrm{Upon} \mathrm{curing,} \mathrm{the}$ samplse were then mounted in a $3.175 \mathrm{~cm}(1.25$ ") round mold for polishing. The cured round mounts were then ground to a base finish with 600 grit paper. The polishing steps included $6 \mu \mathrm{m}$ diamond paste, $1 \mu \mathrm{m}$ diamond paste, and $0.3 \mu \mathrm{m}$ alumina. After polishing, the samples were carbon coated with a Quorum Q-150T coater for conductivity.

Each sample was examined by SEM using a Hitachi SU8030 FE-SEM. Images were captured of the polished particle cross-sections at various magnifications with a voltage of 15 $\mathrm{kV}$. Elemental assays by EDX of the particle cores, outer shells, and other features of interest were performed with a Thermo NORAN System 7 X-ray microanalysis system integrated with the Hitachi SU8030. This includes point EDX, area EDX, and line scans.

\subsubsection{X-ray Photoelectron Spectroscopy (XPS)}

XPS spectra were acquired for the samples created with the fluidized-bed reactor on a Thermo K-Alpha XPS, monochromated Al Ka source with a double-focusing hemispherical analyzer. High resolution spectra were taken of $\mathrm{C} 1 \mathrm{~s}, \mathrm{~N} 1 \mathrm{~s}, \mathrm{O} 1 \mathrm{~s}$, and $\mathrm{Cl} 2 \mathrm{p}$ with 25 total scans at $0.1 \mathrm{eV}$ step size, $50 \mathrm{~ms}$ dwell time, $50 \mathrm{eV}$ pass energy, and $400 \mu \mathrm{m}$ spot size. 


\section{Results and Discussion}

\subsection{Horizontal- and Packed-Bed Reactors}

\subsubsection{Physical Properties}

Figure 1 illustrates the structural evolution of crystalline $\mathrm{TiC}$ to amorphous $\mathrm{TiC}-\mathrm{CDC}$ as a function of reaction time. For both the horizontal- and packed-bed reactors, the carbide peaks appear in all samples until $3.00 \mathrm{~h}$ of etching, when only a broad peak, which is indicative of amorphous carbon, is seen. As the reaction time increases, the intensity of the TiC peaks decreases. This observation combined with an absence of peaks corresponding to $\mathrm{TiO}_{2}$ suggests that the residual metal remains in the $\mathrm{TiC}$ form and $\mathrm{TiCl}_{4}$ is effectively removed from the samples. In addition, the lack of sharp graphitic peaks suggests that Ti does not act as a graphitization catalyst as other metals such as Fe, Co, and Ni (Leis et al., 2002) and that the remaining carbon structure only rearranges to form a narrow pore size distribution as a function of temperature.
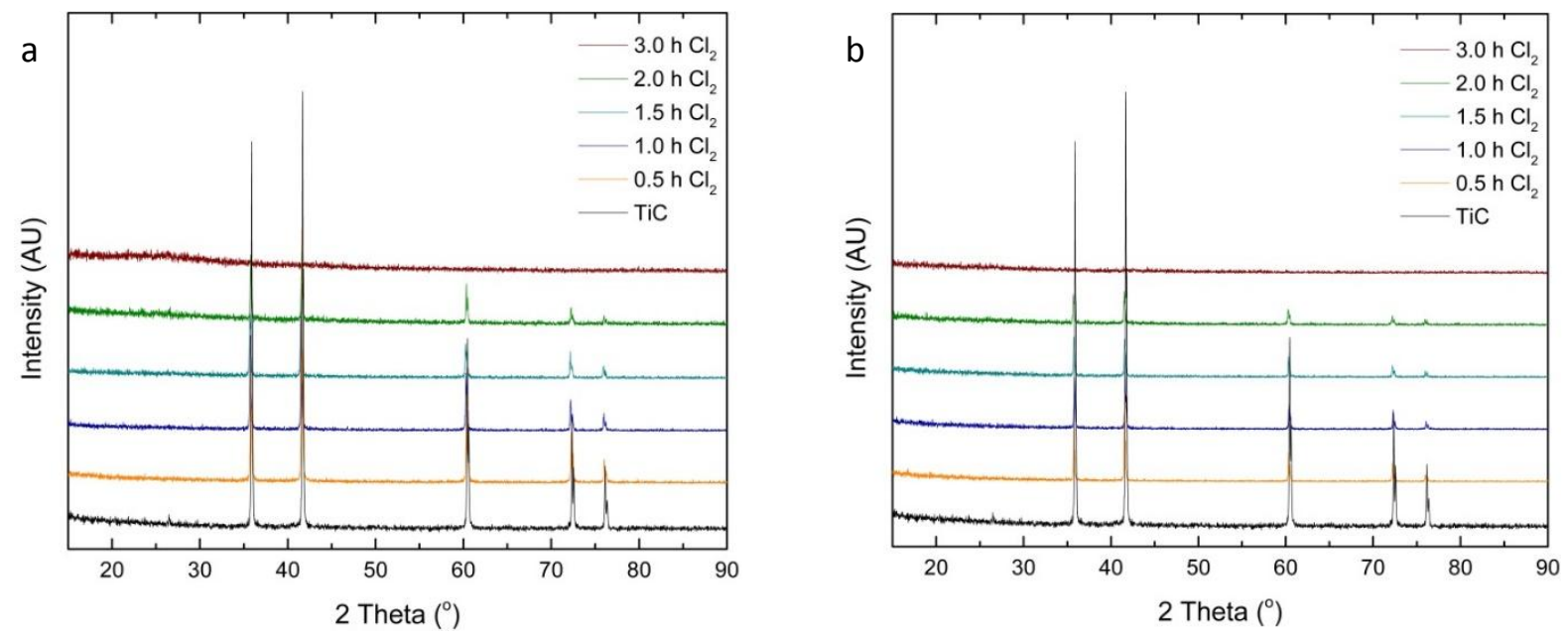

Figure 1 - PXRD patterns for (a) the horizontal-bed reactor and (b) the packed-bed reactor showing the degradation of $\mathrm{TiC}$ structure to the amorphous carbon of the TiC-CDC.

To calculate residual metal loadings, TGA was performed in air to combust the carbon and convert the residual $\mathrm{Ti}$ to $\mathrm{TiO}_{2}$. This resulting $\mathrm{TiO}_{2}$ can be used to calculate the residual $\mathrm{Ti}$ in 
the sample after chlorination. As etching reaction time increases, less residual metal remains in the TiC-CDC structure as shown in Figure 2; however, the two reactors remove Ti at different rates throughout the etching process. The horizontal-bed reactor removes metal more slowly for chlorination times less than $1.00 \mathrm{~h}$ compared to the packed-bed reactor. At etching times greater than $1.00 \mathrm{~h}$, the reaction in the horizontal-bed reactor removes more metal than the comparable reaction in the packed-bed reactor until $3.00 \mathrm{~h}$ of chlorination. At this time, the samples contain minimal residual $\mathrm{Ti}(\sim 5 \mathrm{wt} \%)$. While the chlorination reaction in the horizontal-bed reactor removes $\mathrm{Ti}$ in a sigmoidal fashion, the reaction in the packed-bed reactor removes the metal in a more linear fashion. This could suggest that there are more diffusion limitations in the flow-over horizontal-bed reactor than in the flow-through packed-bed reactor.

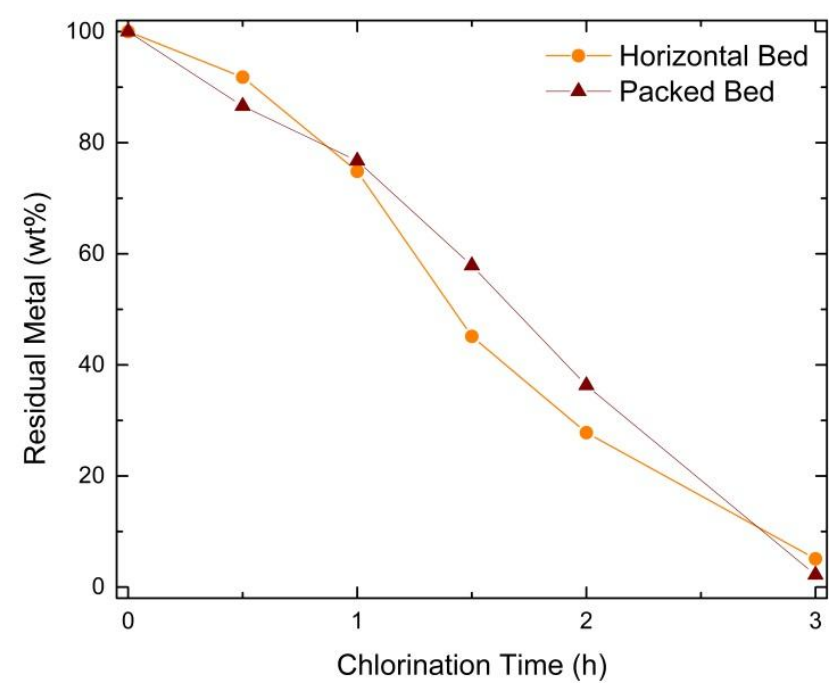

Figure 2 - Residual metal loading as a function of chlorination time for both horizontal- and packed-bed reactor designs.

From $\mathrm{N}_{2}$ adsorption measurements at $77 \mathrm{~K}$, the BET surface areas were calculated and plotted as a function of residual metal as seen in Figure 3. For both the horizontal- and packedbed systems, the surface areas increase as residual metal loading decreases. While the two systems create TiC-CDC samples with similar surface areas for residual metal loadings greater than $75 \mathrm{wt} \%$, which corresponds to etching times less than $1.00 \mathrm{~h}$, the packed-bed reactor 
consistently produces samples with higher BET surface areas at residual metal loadings less than 75 wt $\%$.

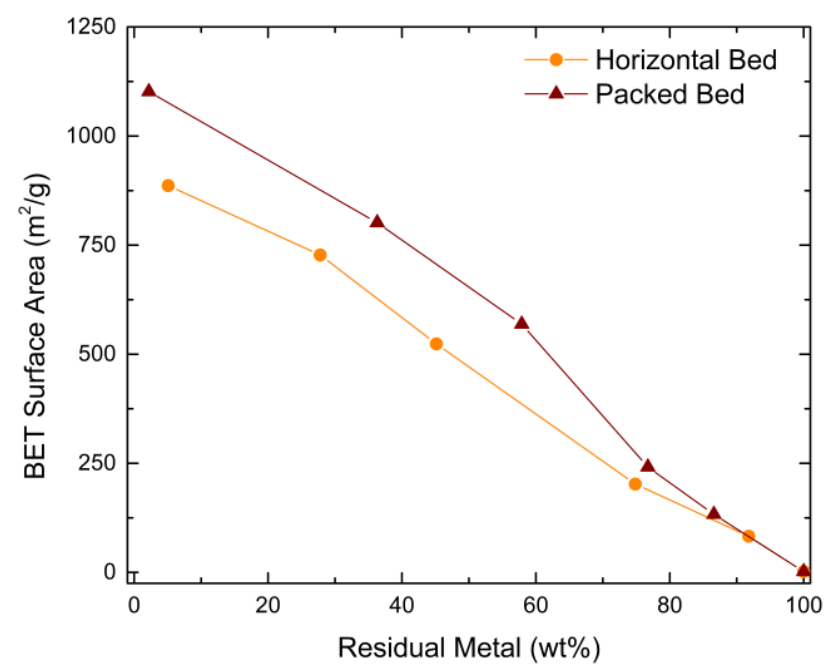

Figure 3 - Comparison of BET surface areas as a function of residual metal for TiC-CDC samples created with horizontal or packed bed reactor systems.

The BET surface area is typically a function of the amount of metal removed and the degree of carbon graphitization. For a specific residual metal loading and carbon arrangement, the BET surface areas should be comparable; therefore, Raman spectra were gathered for select samples to determine the effect that reaction time has on the carbon structure. To determine the carbon structure, two bands are notable: the D-band at $\sim 1350 \mathrm{~cm}^{-1}$ and the G-band at $\sim 1580 \mathrm{~cm}^{-1}$. The D-band corresponds to $\mathrm{a}_{1 \mathrm{~g}}$ stretching that can only be found in aromatic rings, while the Gband corresponds to $\mathrm{e}_{2 \mathrm{~g}}$ stretching, which is found in all $\mathrm{sp}^{2}$ hybridized carbon (Ferrari and Robertson, 2000). The ratio of these intensities $\left(\mathrm{I}_{\mathrm{D}} / \mathrm{I}_{\mathrm{G}}\right)$ is indicative of the degree of carbon ordering. As the $\mathrm{I}_{\mathrm{D}} / \mathrm{I}_{\mathrm{G}}$ ratio does not appreciably change as seen in .

Table 1, we can deduce that the carbon ordering is similar for all TiC-CDC etching times. This implies that the differences seen in BET surface area are not due to differences in carbon ordering but are due to differences in etching mechanics, which are caused by differences in the 
$\mathrm{Cl}_{2}$ flow patterns and concentration gradients through the bed caused by the various reactor designs.

Table $1-I_{D} / I_{G}$ ratios for select samples for the horizontal- and packed-bed reactors.

\begin{tabular}{lll}
\hline Reactor & Sample & $\mathrm{I}_{\mathrm{D}} / \mathrm{I}_{\mathrm{G}}$ Ratio \\
\hline Horizontal-Bed & $0.50 \mathrm{~h} \mathrm{Cl}_{2}$ & $0.88 \pm 0.02$ \\
Reactor & $1.50 \mathrm{~h} \mathrm{Cl}_{2}$ & $0.89 \pm 0.03$ \\
& $3.00 \mathrm{~h} \mathrm{Cl}_{2}$ & $0.89 \pm 0.00$ \\
\hline \multirow{2}{*}{ Packed-Bed } & $0.50 \mathrm{~h} \mathrm{Cl}_{2}$ & $0.89 \pm 0.02$ \\
Reactor & $1.50 \mathrm{~h} \mathrm{Cl}_{2}$ & $0.89 \pm 0.00$ \\
& $3.00 \mathrm{~h} \mathrm{Cl}_{2}$ & $0.89 \pm 0.01$ \\
\hline
\end{tabular}

\subsubsection{Residual Metal Location}

The above results probe the porosity, carbon structure, and residual metal content of TiCCDC prepared at various etching times. However, it does not give insight into where the residual metal remains and in which form. For the horizontal-bed reactor, two distinct layers formed for all etching times shorter than $3.00 \mathrm{~h}$ : (1) a black top layer and (2) a silver, gray bottom layer. These layers initially appeared to correspond to a TiC-CDC top layer and an unreacted TiC bottom layer as their depth would change depending upon chlorination time. To investigate these layers, an additional sample was chlorinated for $1.50 \mathrm{~h}$, and the layers were hand separated and analyzed through PXRD, TGA, $\mathrm{N}_{2}$ adsorption isotherms at $77 \mathrm{~K}$, and SEM/EDX. This is an imperfect separation method, but it produces reasonable data to determine how the etching reaction progresses through the bed. The packed-bed reactor produced samples that appear uniform in color with no obvious layering. As these samples could only be analyzed in bulk, SEM and EDX were utilized to determine residual metal location. 
PXRD patterns in Figure 4 indicate that the top layer, closest to the $\mathrm{Ar} / \mathrm{Cl}_{2}$ flow in the horizontal-bed reactor, is primarily amorphous carbon with low intensity TiC peaks. The PXRD pattern for the bottom layer does not have this broad graphite peak and only contains sharp peaks with high intensities corresponding to TiC. BET surface areas and residual metal loadings point to a similar conclusion. The top layer is highly porous as shown by the high surface area, which is comparable to a fully etched sample. The residual metal loading for the top layer is higher than the fully etched sample; however, this is most likely due to the non-ideal manual separation of the layers. The bottom layer contains almost no porosity and nearly $100 \mathrm{wt} \%$ of residual metal. This indicates that the Ti atoms in the bottom layer did not interact with $\mathrm{Cl}_{2}$. The PXRD patterns along with residual metal loadings and BET surface areas in Table 2 suggest that the initial hypothesis was correct: the horizontal-bed reactor produces samples with a fully etched top layer and an unreacted $\mathrm{TiC}$ bottom layer, which suggests that the reactor has severe $\mathrm{Cl}_{2}$ diffusion limitations.

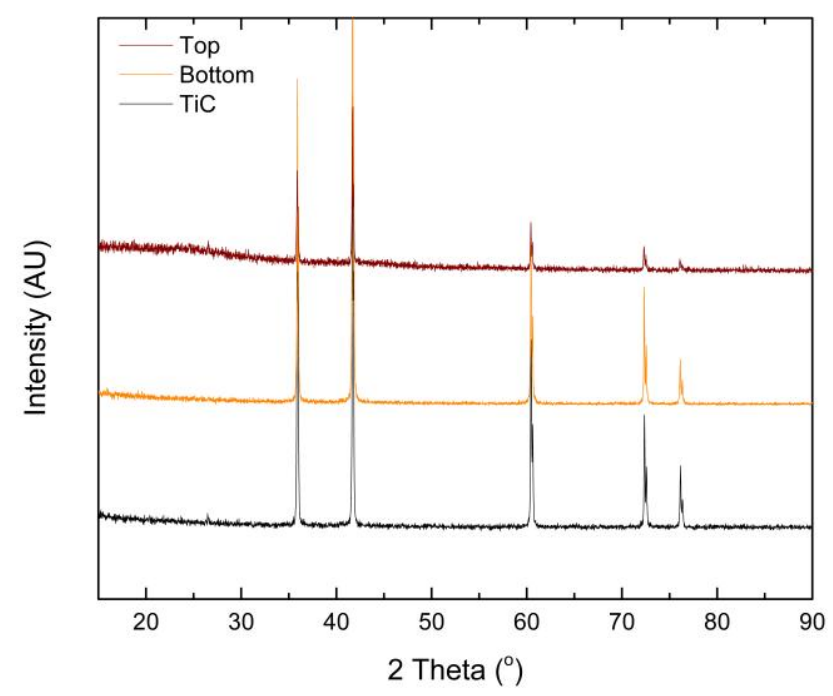

Figure 4 - PXRD patterns for the top and bottom layers created in the horizontal-bed reactor at $500{ }^{\circ} \mathrm{C}$ and etched for $1.50 \mathrm{~h}$. 
Table 2 - Physical properties of manually separated layers for a TiC-CDC sample etched for $1.50 \mathrm{~h}$ along with a fully etched sample using the horizontal-bed reactor.

\begin{tabular}{lll}
\hline Sample & BET Surface Area $\left(\mathrm{m}^{2} / \mathrm{g}\right)$ & $\begin{array}{l}\text { Residual Metal } \\
(\mathrm{wt} \%)\end{array}$ \\
\hline Top & 882 & 18.7 \\
Bottom & 41 & 98.3 \\
$500^{\circ} \mathrm{C}$, etched $3.00 \mathrm{~h}$ & 867 & 4.1 \\
\hline
\end{tabular}

In contrast to the horizontal-bed reactor, the packed-bed reactor produces TiC-CDC samples uniform in color. This initially appeared to indicate that a more uniform etching process was occurring and that perhaps the core-shell model of Ti extraction was observed. SEM and EDX were used to verify this hypothesis. From the SEM images alone, depicted in Figure 5, there is a difference in contrast between the particles. By performing multiple spot scans for EDX, shown in Figure S11, we can conclude that some particles contain residual Ti contents similar to unreacted $\mathrm{TiC}$ particles as in Figure 5a, while others are metal-free as in Figure 5b. This indicates that the packed-bed reactor also has $\mathrm{Cl}_{2}$ diffusion limitations that could be the result of channeling.

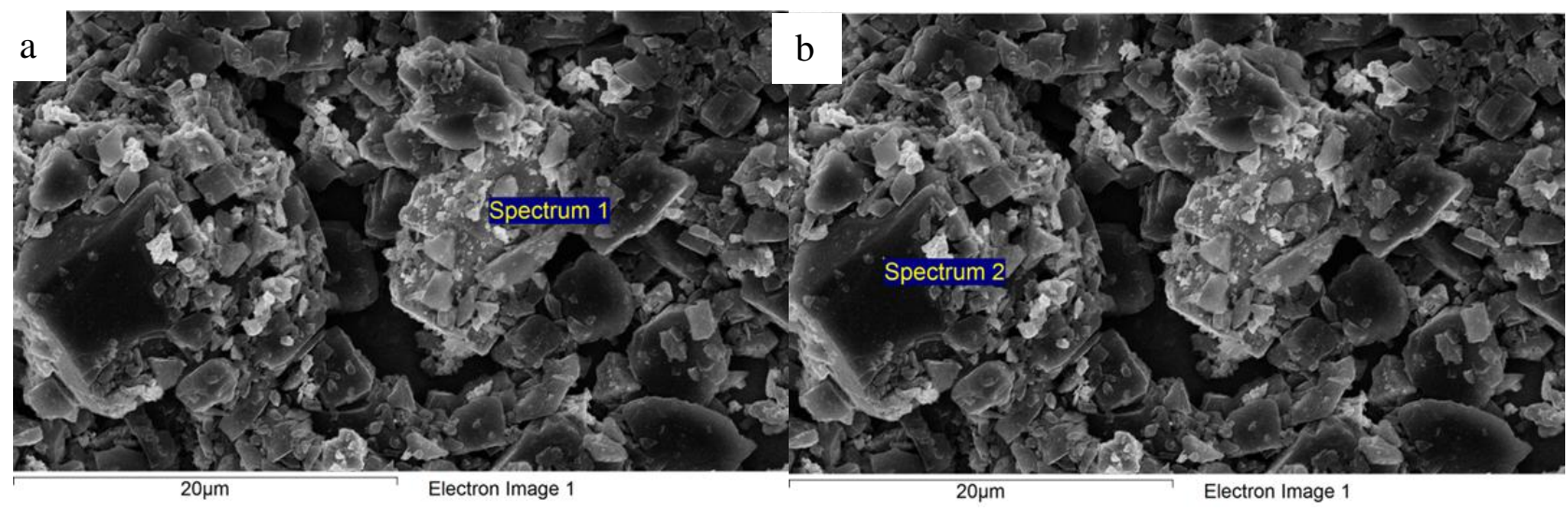

Figure 5-SEM images of a packed-bed reactor sample, where spectrum 1 shows residual Ti and spectrum 2 shows no residual Ti

The above results signify that reactor design influences the etching process through the $\mathrm{TiC}$ reactor bed. The horizontal-bed reactor, by design, is meant to flow the $\mathrm{Cl}_{2}$ gas over the 
sample. For the $\mathrm{Cl}_{2}$ to react with particles at the bottom of the bed, it must diffuse through the bed. However, previous experiments have shown that the reaction between $\mathrm{Ti}$ atoms in $\mathrm{TiC}$ and $\mathrm{Cl}_{2}$ occurs quickly. If the reaction kinetics occur more quickly than $\mathrm{Cl}_{2}$ diffusion through the bed, layering will occur. Indeed, this result occurs for all etching times that result in significant loadings of residual metal. At the shortest chlorination time $(0.25 \mathrm{~h})$, there was a large bottom layer corresponding to unreacted TiC. As the etching time increased, this bottom layer shrank in size until fully disappearing at $3.00 \mathrm{~h}$.

The packed-bed reactor theoretically should minimize the effects from $\mathrm{Cl}_{2}$ diffusion as the $\mathrm{Cl}_{2}$ flows through the bed rather than over it. However, the reactor produces no distinct layers due to $\mathrm{Cl}_{2}$ diffusion limitations nor results in control of the core-shell model. The former would produce top and bottom layers that can be observed by the naked eye in a fully optimized packed-bed reactor. As the $\mathrm{Cl}_{2}$ flowed from the bottom to the top of the reactor, the fully etched region would be the bottom layer, and the unreacted region would be the top layer. As this did not occur, $\mathrm{Cl}_{2}$ diffusion limitations along the bed length were not present here. The latter case also did not occur as shown by the non-uniform etching from particle to particle. The results we found can be explained by channel formation. When $\mathrm{TiC}$ particles are less than $150 \mu \mathrm{m}$ in diameter, the particles often aggregate and form channels where $\mathrm{Cl}_{2}$ flows preferentially. Instead of layers forming in the direction of $\mathrm{Cl}_{2}$ flow, unevenness in etching now preferentially occurs radially from these channels. This results in fully etched particles near and partially or unreacted particles farther away from the channels and the bottom of the bed. This result indicates that the packed-bed reactor is also diffusionally limited. The particles in the transition region, those that are potentially partially etched, most likely explains the difference in BET surface areas and the location of the residual metal in the samples between the horizontal- and packed-bed reactors. 


\subsection{Fluidized-Bed Reactor}

Both the horizontal-bed and packed-bed reactors are limited by $\mathrm{Cl}_{2}$ diffusion through the bed, which inhibits control of the etching reaction. In order to mitigate the $\mathrm{Cl}_{2}$ diffusion limitations, a fluidized-bed reactor was utilized to agitate the particles during the reaction. In a fluidized-bed reactor, the flow rate of the gas through the sample must be high enough to provide enough force to overcome the force of gravity while remaining below the terminal velocity of the particles. The sample is mixed based on the density of the individual particles. Therefore, as the TiC particles are etched, they will become less dense and move away from the $\mathrm{Cl}_{2}$ source allowing for uniform etching throughout the particles. In order to overcome particle aggregation for proper fluidization, $+100-80$ mesh-sized TiC particles were used with higher $\mathrm{Ar}$ and $\mathrm{Cl}_{2}$ flowrates compared to the previous reactor designs.

\subsubsection{Physical Properties}

PXRD patterns in Figure 6 show that the TiC structure quickly changes from the crystalline carbide to amorphous carbon. This degradation occurs more rapidly in the fluidizedbed reactor than for the previous reactors, indicating that metal removal occurs at a higher rate despite a $15 \mathrm{x}$ increase in particle diameter. This higher etching rate could indicate that diffusion limitations seen in the previous reactors are now mitigated as the reaction kinetics and subsequent residual metal loadings should be the same among the three reactors. Similar to the PXRD patterns for previous reactor samples, PXRD patterns for the fluidized-bed reactor samples do not have peaks corresponding to $\mathrm{TiO}_{2}$. As there are no PXRD peaks corresponding to TiC for all etching times, except $0.25 \mathrm{~h}$, we cannot yet conclude the form of residual metal. In contrast to previous PXRD patterns, there is a slight graphite peak at $26^{\circ}$ for samples created with the fluidized-bed reactor. 


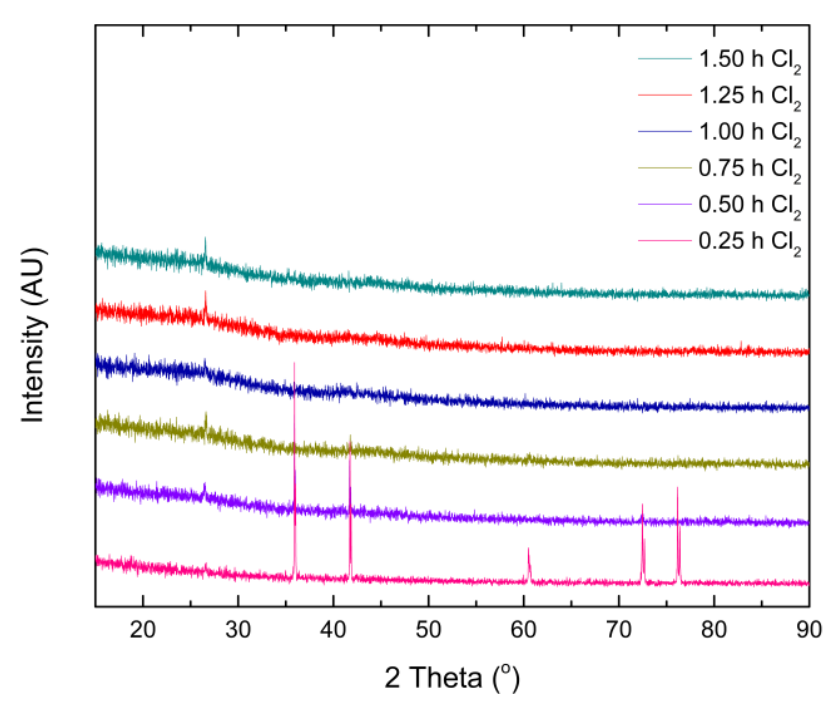

Figure 6 - PXRD patterns showing the degradation of TiC into the amorphous TiC-CDC with a slight peak at $26^{\circ}$ corresponding to graphite.

By plotting the residual metal content as a function of etching time, Figure 7 also shows that $\mathrm{Ti}$ atoms are removed at a faster rate in the fluidized-bed reactor compared to the previous reactors (Figure 2). The shape of the various curves in these figures indicates that metal removal rate is a function of the flow patterns. Unlike the previous reactors, where the rate of metal removal was linear, the fluidized-bed reactor quickly removes Ti until $0.75 \mathrm{~h}$ of etching, when the removal rate drops significantly. As these particles are 15x larger in diameter than those used in the previous reactors, this observation can be attributed to internal particle diffusion limitations rather than interparticle diffusion limitations (Becker et al., 2010); however, this does not appear to occur until there is $\sim 5 \mathrm{wt} \%$ residual Ti. 


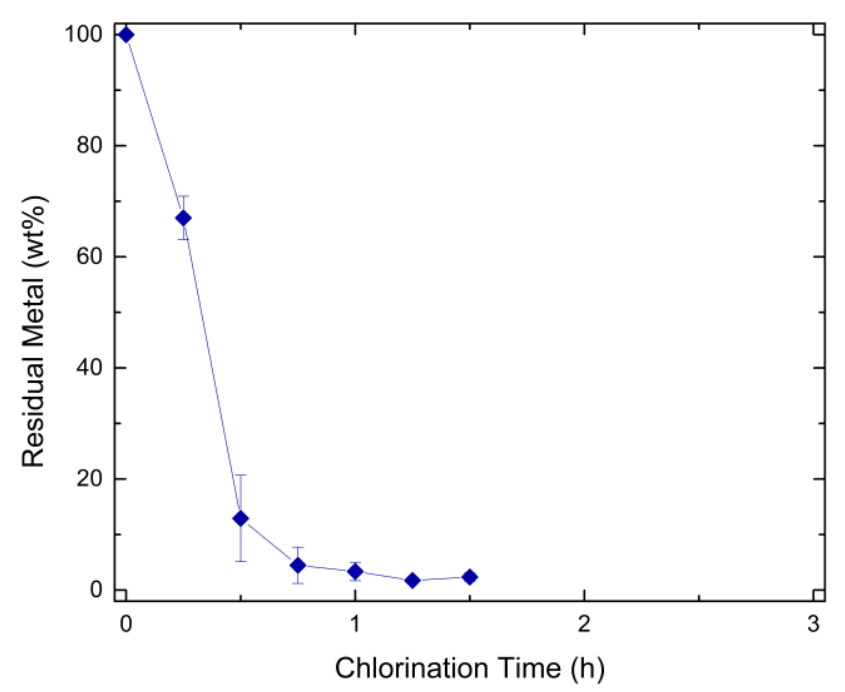

Figure 7 - Residual metal loading (wt \%) as a function of etching time (h) for the fluidized-bed reactor.

The porosity of the larger TiC-CDC particles was determined through $\mathrm{N}_{2}$ adsorption at 77 K. The BET surface areas (Figure 8a) have a linear relationship with respect to decreasing residual metal loading. The maximum BET surface area for samples created with the fluidizedbed reactor correspond well with the maximum surface area for samples synthesized in the packed-bed reactor. The linear relationship between residual metal loading and surface area indicates that etching proceeds without significant intraparticle diffusional limitations and that there are minimal diffusion limitations through the particles or the fluidized bed. This suggests that the core-shell model of metal extraction occurs for these samples.

To determine a pore size distribution (PSD), QSDFT calculations were applied to the $\mathrm{N}_{2}$ adsorption isotherms. For etching times $1.00 \mathrm{~h}$ and less, there is a unimodal distribution, as seen in Figure 8b. However, for etching times greater than $1.00 \mathrm{~h}$, there is a bimodal distribution with each mode centered on $\sim 3$ and $\sim 5 \AA$ in pore radius. To gain a better understanding of this phenomenon, three additional samples were etched for $0.25,0.50$ and $0.75 \mathrm{~h}$ and then maintained at $500{ }^{\circ} \mathrm{C}$ under pure Ar flow for a total duration of $1.50 \mathrm{~h}$. For these additional samples, the bimodal PSD appears which indicates the PSD is also a function of time and not just 
temperature. This additional time at high temperatures appears to allow the development of structural changes in the carbon that are unrelated to removing $\mathrm{Ti}$ atoms from the structure. Figure 8d shows PSDs that were also calculated using $\mathrm{CO}_{2}$ adsorption at $273 \mathrm{~K}$ to gain further insight in the micropore region. While QSDFT calculations with $\mathrm{N}_{2}$ adsorption isotherms are limited to pore sizes $\sim 3 \AA$ in radius, NLDFT calculations with $\mathrm{CO}_{2}$ adsorption isotherms shows additional pores $1.79 \AA$ in radius. Both models indicate that the PSD is narrow and all pores are microporous as is typical for TiC-CDCs etched at $500{ }^{\circ} \mathrm{C}$. 

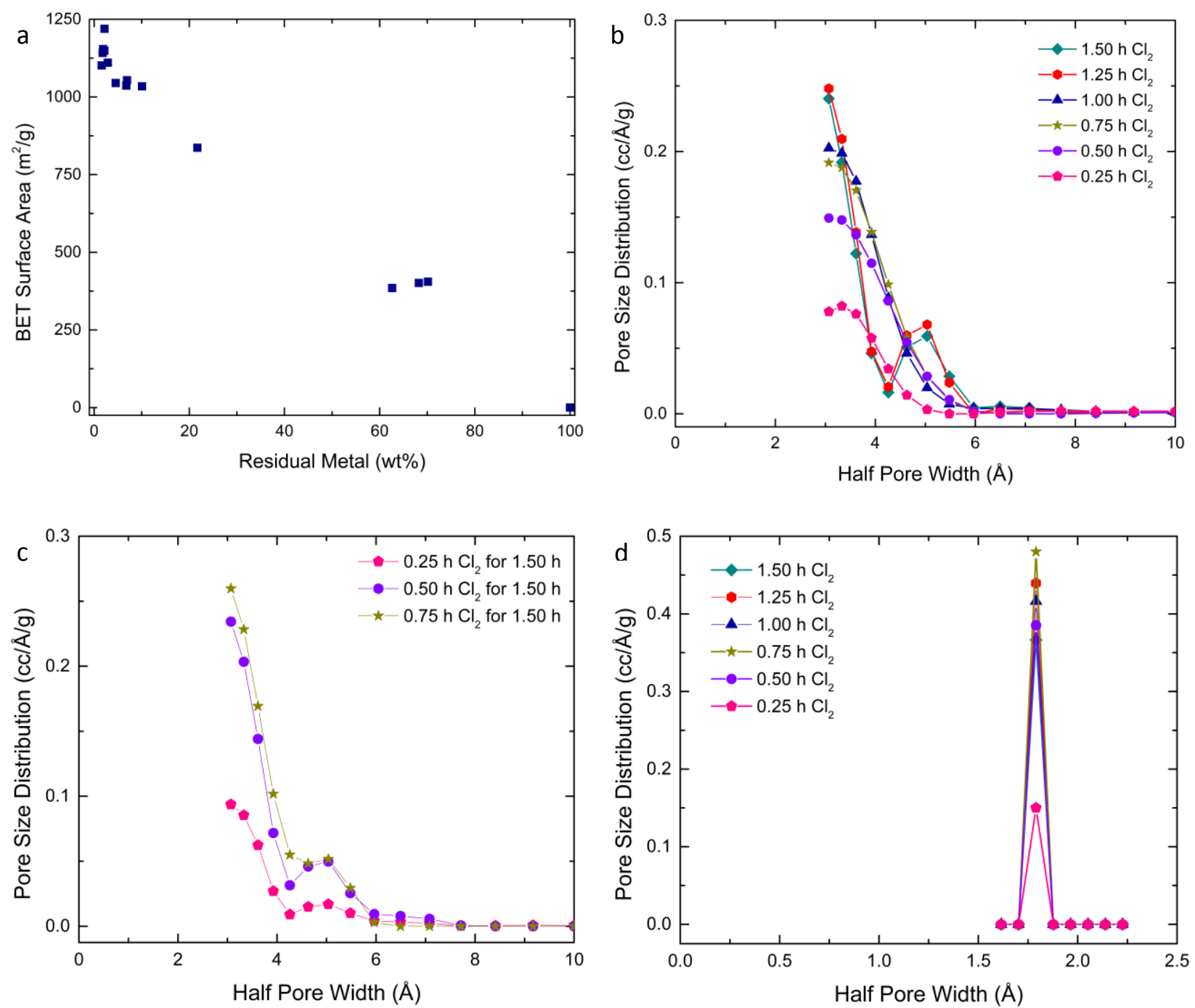

Figure 8 - Characterization of fluidized-bed reactor samples including (a) BET surface area for 150-180 $\mu \mathrm{m}$ TiC-CDC particles as a function of residual Ti loading, (b) pore size distributions for various chlorination times calculated with QSDFT using $\mathrm{N}_{2}$ adsorption isotherms at $77 \mathrm{~K}$, (c) pore size distributions for samples etched for less than $1.00 \mathrm{~h}$ and held at $500{ }^{\circ} \mathrm{C}$ for a total time at $1.50 \mathrm{~h}$, and (d) pore size distributions for various chlorination times calculated with NLDFT using $\mathrm{CO}_{2}$ adsorption isotherms at $298 \mathrm{~K}$.

Table $3-\mathrm{I}_{\mathrm{D}} / \mathrm{I}_{\mathrm{G}}$ ratios for select samples created with the fluidized-bed reactor.

\begin{tabular}{ll}
\hline Sample & $\mathrm{I}_{\mathrm{D}} / \mathrm{I}_{\mathrm{G}}$ Ratio \\
\hline $0.25 \mathrm{~h} \mathrm{Cl}_{2}$ & $0.64 \pm 0.28$ \\
$0.75 \mathrm{~h} \mathrm{Cl}_{2}$ & $0.78 \pm 0.24$ \\
$1.50 \mathrm{~h} \mathrm{Cl}_{2}$ & $0.85 \pm 0.09$ \\
$0.25-1.50 \mathrm{~h} \mathrm{Cl}_{2}$ & $0.90 \pm 0.00$ \\
$0.75-1.50 \mathrm{~h} \mathrm{Cl}_{2}$ & $0.82 \pm 0.18$ \\
\hline
\end{tabular}


Table 4 - Composition of elements and types of bonds (atomic \%), acquired by processing XPS spectra, within TiC-CDC etched for various times in the fluidized-bed reactor

\begin{tabular}{llllllll}
\hline & TiC & $0.25 \mathrm{~h}$ & $0.50 \mathrm{~h}$ & $0.75 \mathrm{~h}$ & $1.00 \mathrm{~h}$ & $1.25 \mathrm{~h}$ & $1.50 \mathrm{~h}$ \\
\hline $\begin{array}{l}\text { Element } \\
\text { Bond }\end{array}$ & \multicolumn{7}{c}{ Atomic $\%$} \\
\hline $\mathrm{C}$ & 39.8 & 83.4 & 78.3 & 80.6 & 78.4 & 81.7 & 79.9 \\
$\mathrm{C}=\mathrm{C}$ & - & 60.8 & 58.6 & 64.6 & 54.1 & 42.5 & 56.9 \\
$\mathrm{C}-\mathrm{C}$ & - & 0 & 17.1 & 0 & 20.5 & 24.4 & 19.4 \\
$\mathrm{C}-\mathrm{N}$ & - & 17.8 & 12.5 & 16.9 & 8.9 & 13.6 & 5.3 \\
$\mathrm{C}-\mathrm{O}$ & - & 8.1 & 6.9 & 6.4 & 5.4 & 4.3 & 3.6 \\
$\mathrm{C}=\mathrm{N}, \mathrm{C}=\mathrm{O}$ & - & 5.6 & 4.7 & 4.5 & 4.2 & 4.8 & 3.7 \\
$\mathrm{C}-\mathrm{Cl}$ & - & 4.8 & 4.0 & 4.7 & 4.1 & 7.3 & 8.7 \\
$\mathrm{C}-\mathrm{Cl}$ & - & 3.1 & 2.7 & 3.0 & 2.9 & 3.0 & 2.4 \\
$\mathrm{Cl}$ & - & 5.8 & 7.7 & 6.9 & 8.4 & 8.5 & 7.8 \\
$\mathrm{O}$ & 35.7 & 5.4 & 4.8 & 5.9 & 6.0 & 3.9 & 5.4 \\
$\mathrm{~N}$ & 4.1 & 5.4 & 9.0 & 6.6 & 7.2 & 5.9 & 6.9 \\
$\mathrm{Ti}$ & 20.4 & - & - & - & - & - & - \\
\hline
\end{tabular}

Further insight into the structure including terminal groups on the carbon was gained through Raman spectroscopy and XPS. The $\mathrm{I}_{\mathrm{D}} / \mathrm{I}_{\mathrm{G}}$ ratio gives an indication to the degree of carbon ordering. In Table 3 there is wide variation in the $\mathrm{I}_{\mathrm{D}} / \mathrm{I}_{\mathrm{G}}$ ratios, where, as time increases, the degree of graphitization decreases. The wide variation within a sample is indicative that this graphitization does not occur evenly throughout the sample possibly due to the large particle sizes and short reaction times. Indeed as the etching time increases, the additional time allows the carbon to reorganize completely throughout a particle, which results in a lower error. When etching a sample for a short period and then holding the sample at $500{ }^{\circ} \mathrm{C}$ for a total time of 1.50 $h$, the carbon also has the ability to reorganize fully as evident in the higher $I_{D} / I_{G}$ ratio and lower error. This additional organization fully explains the differences seen in the PSD in Figure $8 b$. The XPS spectra show that $40-60$ atomic $\%$ of the surface is $\mathrm{sp}^{2}$ hybridized carbon with additional bonds to chlorine (6-10 atomic \%), oxygen (7-13 atomic \%), and nitrogen (8-20 atomic \%). Carbon-chlorine bonds are due to the reaction itself. While the Ti and $\mathrm{Cl}_{2}$ reaction is favored at the high reaction temperature, a small amount of $\mathrm{Cl}^{-}$ions reacts with unpaired carbon 
electrons while carbon is reorganizing itself around the Ti vacancy. Oxygen bonds most likely occur due to a passive layer of oxygen on the carbide surface before etching occurs. Most likely these $\mathrm{C}-\mathrm{O}$ bonds are located only on the surface as this is where the carbide passivation occurs. Nitrogen bonds are most likely due to exposure to air after the etching reaction occurs.

\subsubsection{Residual Metal Location}

SEM images were taken of the cross-sections of select samples synthesized with the fluidized-bed reactor, and EDX spectra were gathered to determine the elemental identity of the layers formed within TiC-CDC particles. Figure 9 shows that the fluidized-bed reactor controls the core-shell model of Ti extraction. The TiC precursor is cleaved in half and generally shows no cracking from the grinding process due to the physical properties of TiC. In Figure 9a and b, the core appears to shrink as the reaction time increases. The shape of the TiC core further supports the layer-by-layer titanium extraction method as the core follows the contour of the particle and the TiC-CDC shell has a uniform thickness. Figure 9d shows that etching for $1.50 \mathrm{~h}$ completely removes the $\mathrm{TiC}$ core. Here the particle contains cracks due to the grinding process used to create these cross-sections. As TiC-CDC is a porous material, air pockets appear between the particle and the resin during the preparation steps.

EDX spectra in Figures S18-S21 determine that the core of the particles is TiC, while the shell is comprised of primarily $\mathrm{C}$ with $\mathrm{Cl}$, O, and $\mathrm{N}$ species. XPS spectra (Figures S13-17) previously determined the bonds between these four elements. The TiC core in Figure 9c appears to be off center; however, this is due to particle shape and the grinding method. Based upon EDX results we can conclude that the core extends to the left underneath the TiC-CDC layer in an iceberg-like formation. We cannot conclude how far this core extends as EDX only penetrates 1- 
$3 \mu \mathrm{m}$ in depth. Similarly, there is no conclusive evidence of a transition region between the TiC core and TiC-CDC shell.

TGA data combined with the SEM preparation method used to create the cross-sections of the $\mathrm{TiC}-\mathrm{CDC}$ particles highly suggest that as the etching time increases the $\mathrm{TiC}$ core decreases in size. We cannot definitively conclude that the TiC-CDC particles are uniformly etched within a sample based purely upon the limitations of this SEM preparation method. As not all particles are of equal size, the amount of grinding to create this cross-section is not equal for all particles. For this reason, depending on where the cross-section is taken, similar results for different samples are a possibility. However, an understanding of the flow patterns within the fluidizedbed reactor suggests that these samples are more uniformly etched than samples prepared with the horizontal- and packed-bed reactors. 

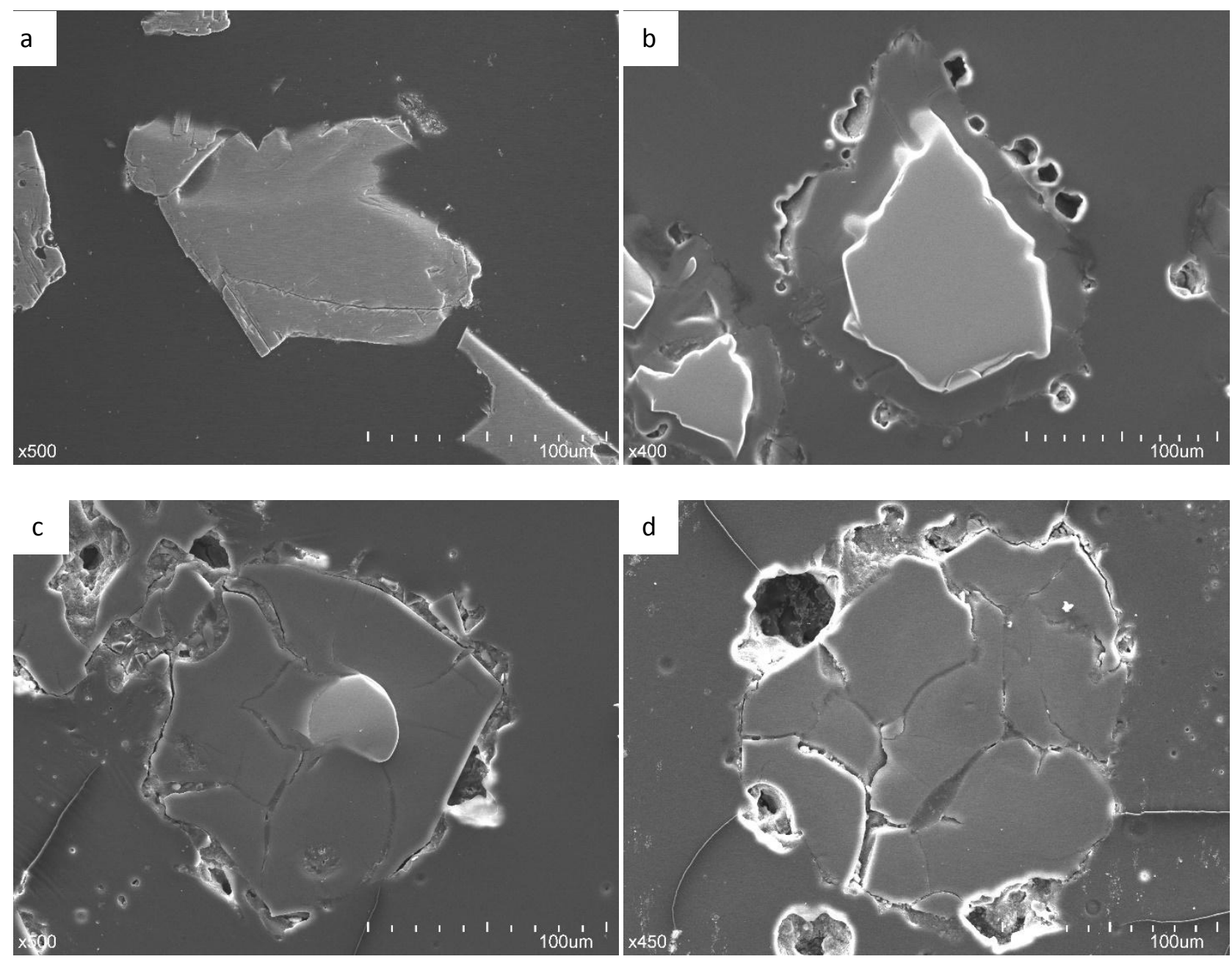

Figure 9 - SEM images of a) TiC, b) TiC-CDC etched for $0.25 \mathrm{~h}$, c) TiC-CDC etched for $0.75 \mathrm{~h}$, and d) TiC-CDC etched for $1.50 \mathrm{~h}$ showing that the $\mathrm{TiC}$ core shrinks as reaction time increases. Pockets between the TiC-CDC shell and the resin are air pockets due to the porous nature of TiC-CDC.

The physical properties and residual metal location are directly related to the gas flow within the fluidized-bed reactor. The reaction between $\mathrm{Cl}_{2}$ and $\mathrm{Ti}$ naturally creates a $\mathrm{Cl}_{2}$ concentration gradient along the bed length. The highest concentration of $\mathrm{Cl}_{2}$ is at the bottom, while the lowest concentration is at the top of the bed. The flow within the fluidized-bed reactor separates particles based upon density: denser particles sink to the bottom of the reactor bed as the force from the fluid is not enough to counteract gravity, while less dense particles rise to the top of the bed. TiC-CDC particles change density as metal is removed; therefore, particles that 
contain less Ti rise to the top of the bed, while particles with more residual Ti sink to the bottom. Since dense particles with more residual Ti are located where the $\mathrm{Cl}_{2}$ concentration is highest, these particles will undergo etching at a greater rate than the less dense particles located where the $\mathrm{Cl}_{2}$ concentration is lowest. Once enough metal is etched, the density decreases and these now lighter particles rise to the top of the bed. This mixing appears sufficient to uniformly etch the particles within the bed and reduce any effects caused by the $\mathrm{Cl}_{2}$ concentration gradient .

\section{Conclusions}

Three reactor designs and their capacity to partially etch TiC-CDC were investigated. While each reactor produced partially etched samples, their effectiveness was not uniform. The horizontal-bed reactor produced samples consisting of two layers: (1) a fully-etched top layer consisting of pure TiC-CDC and (2) an unreacted bottom layer of TiC. This layering occurs due

to diffusional limitations through the bed in the flow-over design. The packed-bed reactor produced samples consistent in color; however, further inspection revealed that the particles were not uniformly etched. Channeling in the reactor bed created particles with a gradient of residual metal; as the distance from the channels increased, the more residual metal remained. Even if channels had not formed within the packed bed, it is unlikely that the resulting samples would have been uniformly etched as there was no mixing of particles to alleviate effects from the $\mathrm{Cl}_{2}$ concentration gradient. Both the horizontal- and packed-bed reactors are significantly diffusion limited. Alternatively, the fluidized-bed reactor etched TiC following a core-shell mechanism of $\mathrm{Ti}$ removal to leave a $\mathrm{TiC}$ core with a fully etched $\mathrm{TiC}-\mathrm{CDC}$ shell. $\mathrm{The} \mathrm{Cl}_{2}$ concentration gradient proved beneficial for the density-based separation and mixing that occurred within the fluidized bed as the reaction proceeded. Samples synthesized with the fluidized-bed reactor had high surface areas, uniform pore size distributions, and surface groups 
due to a passive oxide layer on the $\mathrm{TiC}$ precursor and $\mathrm{Cl}^{-}$ions reacting with unpaired $\mathrm{C}$ electrons.

To control the core-shell mechanism of Ti extraction and leave behind residual Ti, the fluidizedbed reactor was the most successful in creating uniform properties throughout the bed.

\section{Acknowledgements}

This work was supported as part of UNCAGE-ME, an Energy Frontier Research Center funded by the U.S. Department of Energy, Office of Science, Basic Energy Sciences under Award no. DE-SC0012577. The authors would like to acknowledge Colton Moran and Cody Morelock for collecting PXRD patterns and G. Walton Collins for preparing and gathering SEM images and EDX spectra of the cross-sections for samples created with the fluidized-bed reactor.

\section{Works Cited}

Bandosz, T.J., Jagiełło, J., Schwarz, J. a., Krzyzanowski, A., 1996. Effect of Surface Chemistry on Sorption of Water and Methanol on Activated Carbons. Langmuir 12, 6480-6486. doi:10.1021/la960340r

Becker, P., Glenk, F., Kormann, M., Popovska, N., Etzold, B.J.M., 2010. Chlorination of titanium carbide for the processing of nanoporous carbon: A kinetic study. Chem. Eng. J. 159, 236-241. doi:10.1016/j.cej.2010.02.011

Borchardt, L., Hasché, F., Lohe, M.R., Oschatz, M., Schmidt, F., Kockrick, E., Ziegler, C., Lescouet, T., Bachmatiuk, A., Büchner, B., Farrusseng, D., Strasser, P., Kaskel, S., 2012. Transition metal loaded silicon carbide-derived carbons with enhanced catalytic properties. Carbon N. Y. 50, 1861-1870. doi:10.1016/j.carbon.2011.12.036

Carter, E.M., Katz, L.E., Speitel, G.E., Ramirez, D., 2011. Gas-phase formaldehyde adsorption isotherm studies on activated carbon: correlations of adsorption capacity to surface functional group density. Environ. Sci. Technol. 45, 6498-503. doi:10.1021/es104286d

Chmiola, J., Yushin, G., Gogotsi, Y., Portet, C., Simon, P., Taberna, P.L., 2006. Anomalous Increase in Carbon Capacitance at Pore Sizes Less Than 1 Nanometer. Science 313, 17603. doi:10.1126/science.1132195

Ferrari, a., Robertson, J., 2000. Interpretation of Raman spectra of disordered and amorphous carbon. Phys. Rev. B 61, 14095-14107. doi:10.1103/PhysRevB.61.14095

Glenk, F., 2012. Synthese von karbidabgeleiteten Kohlenstoffmaterialien im Wirbelschichtreaktor.

Gogotsi, Y., Nikitin, A., Ye, H., Zhou, W., Fischer, J.E., Yi, B., Foley, H.C., Barsoum, M.W., 2003. Nanoporous carbide-derived carbon with tunable pore size. Nat. Mater. 2, 591-4. 
doi:10.1038/nmat957

Gor, G.Y., Thommes, M., Cychosz, K.A., Neimark, A. V., 2012. Quenched solid density functional theory method for characterization of mesoporous carbons by nitrogen adsorption. Carbon N. Y. 50, 1583-1590. doi:10.1016/j.carbon.2011.11.037

Hanson, D.M., Stockbauer, R., Madey, T.E., 1982. The interaction of methanol with a titanium(001) surface investigated using photon stimulated desorption and UV photoemission spectroscopy. J. Chem. Phys. 77, 1569-1575. doi:10.1063/1.443939

Johns, M.M., Marshall, W.E., Toles, C.A., 1998. Agricultural By-products as Granular Activated Carbons for Adsorbing Dissolved Metals and Organics. J. Chem. Technol. Biotechnol. 71, 131-140. doi:10.1002/(SICI)1097-4660(199802)71:2<131::AID-JCTB821>3.0.CO;2-K

Kleitz, F., Bérubé, F., Guillet-Nicolas, R., Yang, C.M., Thommes, M., 2010. Probing adsorption, pore condensation, and hysteresis behavior of pure fluids in three-dimensional cubic mesoporous KIT-6 silica. J. Phys. Chem. C 114, 9344-9355. doi:10.1021/jp909836v

Leis, J., Perkson, A., Arulepp, M., Nigu, P., Svensson, G., 2002. Catalytic effects of metals of the iron subgroup on the chlorination of titanium carbide to form nanostructural carbon. Carbon N. Y. 40, 1559-1564.

Liu, H., Lian, Z., Ye, X., Shangguan, W., 2005. Kinetic analysis of photocatalytic oxidation of gas-phase formaldehyde over titanium dioxide. Chemosphere 60, 630-5. doi:10.1016/j.chemosphere.2005.01.039

Mangarella, M.C., Ewbank, J.L., Dutzer, M.R., Alamgir, F.M., Walton, K.S., 2014. Synthesis of embedded iron nanoparticles in Fe3C-derived carbons. Carbon N. Y. 79, 74-84. doi:10.1016/j.carbon.2014.07.044

Matisová, E., Škrabáková, S., 1995. Carbon sorbents and their utilization for the preconcentration of organic pollutants in environmental samples. J. Chromatogr. A. doi:10.1016/0021-9673(95)00347-P

Neimark, A. V., Lin, Y., Ravikovitch, P.I., Thommes, M., 2009. Quenched solid density functional theory and pore size analysis of micro-mesoporous carbons. Carbon N. Y. 47, 1617-1628. doi:10.1016/j.carbon.2009.01.050

Otowa, T., Nojima, Y., Miyazaki, T., 1997. Development of KOH activated high surface area carbon and its application to drinking water purification. Carbon N. Y. 35, 1315-1319. doi:10.1016/S0008-6223(97)00076-6

Portet, C., Lillo-Ródenas, M.A., Linares-Solano, A., Gogotsi, Y., 2009. Capacitance of KOH activated carbide-derived carbons. Phys. Chem. Chem. Phys. 11, 4943-5. doi:10.1039/b816514a

Presser, V., Heon, M., Gogotsi, Y., 2011. Carbide-Derived Carbons - From Porous Networks to Nanotubes and Graphene. Adv. Funct. Mater. 21, 810-833. doi:10.1002/adfm.201002094

Presser, V., McDonough, J., Yeon, S.-H., Gogotsi, Y., 2011c. Effect of pore size on carbon 
dioxide sorption by carbide derived carbon. Energy Environ. Sci. 4, 3059-3066.

doi:10.1039/c1ee01176f

Rezaee, A., Rangkooy, H., Khavanin, A., Jafari, A.J., 2014. High photocatalytic decomposition of the air pollutant formaldehyde using nano-ZnO on bone char. Environ. Chem. Lett. 12, 353-357. doi:10.1007/s10311-014-0453-7

Rychlicki, G., Terzyk, A., 1998. The influence of carbon surface oxidation on the adsorption of methanol and ethanol. J. Therm. Anal. Calorim. 54, 343-350.

doi:10.1023/A:1010178616042

Tsoncheva, T., Genova, I., Tsyntsarski, B., Dimitrov, M., Paneva, D., Cherkezova-Zheleva, Z., Budinova, T., Ivanova, R., Mitov, I., Petrov, N., 2014. Cobalt and iron modified activated carbon from coal tar pitch: preparation and application as catalysts for methanol decomposition. J. Porous Mater. 21, 503-512. doi:10.1007/s10934-014-9797-4

Xu, J., Zhang, R., Ge, S., Wang, J., Liu, Y., Chen, P., 2013. Effect of iron catalyst on the microstructure and electrochemical properties of vanadium carbide-derived carbons. Mater. Chem. Phys. 141, 540-548. doi:10.1016/j.matchemphys.2013.05.059

Yushin, G., Nikitin, A., Gogotsi, Y., 2006. Carbide-Derived Carbon, in: Gogotsi, Y. (Ed.), Nanomaterials Handbook. CRC Press, Boca Raton, FL, pp. 237-280.

doi:10.1201/9781420004014.ch8 